\title{
DERECHOS IMPLÍCITOS Y CORTE INTERAMERICANA DE DERECHOS HUMANOS: UNA REFLEXIÓN A LA LUZ DE LA NOCIÓN DE ESTADO DE DERECHO
}

\author{
UNENUMERATED RIGHTS AND THE INTER-AMERICAN COURT \\ OF HUMAN RIGHTS: A REFLECTION IN THE LIGHT OF \\ THE RULE OF LAW
}

\section{Gonzalo Candia Falcón ${ }^{*}$}

\begin{abstract}
RESUMEN: La Corte Interamericana de Derechos Humanos, dado el carácter general y vago de muchas de las normas de la Convención Americana, ha comenzado una tendencia jurisprudencial que, bajo clave interpretativa, ha incorporado tácitamente nuevas garantías al listado de derechos comprendidos en la Convención. Ello hace surgir la interrogante acerca de la extensión del ámbito de competencia ratione materiae de la Corte. En efecto, es necesario determinar si en el referido proceso la Corte ha ido más allá de lo pactado por los estados y, de esta forma, excede su facultad interpretativa a través de la creación de nuevos derechos. El autor propone que hay razones para prescindir de esta tendencia, las cuales provienen de la noción de estado de Derecho que el mismo sistema interamericano pretende observar.
\end{abstract}

Palabras clave: Corte Interamericana de Derechos Humanos, derechos implícitos, discrecionalidad judicial, Estado de Derecho.

ABSTRACT: By applying the vague and general provisions of the American Convention to concrete cases, the Inter-American Court of Human Rights has incorporated new rights ("implied rights") to the text of the treaty. In doing so, the Court has expanded its ratione materiae jurisdiction. The author argues that this practice challenges the main assumptions of the rule of law. In effect, the Court's creative activity has eroded the legality principle, by which adjudicators must follow the mechanisms and procedures of amendment previously defined by law. Finally, the article promotes judicial self-restraint by referring some factors whose ends are, precisely, to impose limits on the Court's powers.

Key words: Inter-American Court of Human Rights, implied rights, judicial discretion, rule of law.

\section{INTRODUCCIÓN}

Aun cuando la Convención Americana sobre Derechos Humanos (en adelante "la Convención”) ha establecido un catálogo de derechos que los Estados firmantes están obli-

"Licenciado en Derecho por la Pontificia Universidad Católica de Chile. Abogado. Magíster en Derecho y Doctor en Derecho (S.J.D) por la Universidad de Georgetown. Profesor de Derecho Constitucional y Derechos Humanos en la Pontificia Universidad Católica de Chile. Dirección postal: Alameda 340, Santiago. E-mail: gfcandia@uc.cl. El autor agradece a los ayudantes Juan Lagos y Nelson Díaz por su destacada colaboración en la elaboración del presente artículo. El mismo se enmarca dentro del proyecto de investigación Inicio de la Vicerrectoría de Investigación de la Pontificia Universidad Católica de Chile VRI No 26/2014 2014 titulado "La teoría de los derechos implícitos en el Derecho Constitucional chileno y comparado. Estudio y análisis dogmático-constitucional”, del cual el autor es investigador responsable. 
gados a garantizar, dicho listado ha sido expandido a partir de una práctica de la Corte Interamericana de Derechos Humanos (en adelante, "CIADH" o "la Corte") destinada a desarrollar lo que ha venido en denominarse derechos implícitos. Este modo de proceder de la Corte no es del todo pacífico, puesto que la adición de derechos implícitos al catálogo protegido por la Convención a través de la vía judicial presenta interrogantes que deben ser resueltas si se espera que el actuar de la Corte y su justificación doctrinal sean fundamentados racionalmente.

En el presente artículo se sostendrá que hay buenas razones para prescindir de la práctica desarrollada por la CIADH en relación a los derechos implícitos. Razones que, amparadas por la noción de estado de Derecho que la propia CIADH pretende observar y, respecto de la interpretación en comento, justifican las interrogantes que la hacen cuestionable y entrega las bases que la hacen prescindible.

Para estos efectos se describirá la práctica del reconocimiento de derechos implícitos por parte de la CIADH y algunas instancias de la misma (2). Luego se demostrará que esta práctica no supone un ejercicio hermenéutico del texto de la Convención, sino derechamente un acto de creación normativa que expande las competencias ratione materiae de la Corte (3), para así concluir que aquella práctica es incompatible con la noción de estado de Derecho que la Convención y la Corte pretenden observar (4). Finalmente, se señalará que el mismo sistema interamericano presenta alternativas conformes a la noción de estado de Derecho que permiten prescindir de la interpretación controvertida que supone la práctica del reconocimiento de los derechos implícitos (5).

\section{INTERPRETACIÓN DE LA CONVENCIÓN Y SUS CONSECUENCIAS}

En el presente apartado se examinarán los mecanismos a través de los cuales la $\mathrm{CIADH}$ ha interpretado el texto de la Convención, reconociendo la existencia de derechos implícitos en la misma.

\subsection{CIADH: Derechos explícitos E implícitos EN la CONVEnción Americana}

La jurisdicción ratione materiae de la CIAHD se extiende, tal como lo señala el artículo 62.1 de la Convención Americana, a todos aquellos «casos relativos a la interpretación o aplicación de esta Convención». En ese sentido, y tal como lo agrega el artículo 63, "cuando [la CIADH] decida que hubo violación de un derecho o libertad protegidos en esta Convención, la Corte dispondrá que se garantice al lesionado en el goce de su derecho o libertad conculcados». En este contexto surgen las interrogantes acerca de cuáles son, según lo señalado por el artículo 63, los «derechos y libertades protegidos por [la Convención]».

En principio, existe claridad respecto a que los derechos y libertades protegidos por la Convención son, en primer lugar, aquellos indicados de forma expresa en su texto. La CIADH ha entendido, asimismo, que la jurisdicción ratione materiae de la Corte se extiende también a la interpretación y aplicación de otros instrumentos interamericanos que le hubiesen reconocido jurisdicción ${ }^{1}$, tales como la Convención Interamericana contra la 
Desaparición Forzada de Personas o el Protocolo de San Salvador. Dicha atribución no se extendería, por tanto, a aquellos tratados de derechos humanos que no reconocieran, implícita o explícitamente, jurisdicción a la Corte ${ }^{2}$.

Ahora bien, en lo que respecta a los derechos reconocidos expresamente en la Convención, la $\mathrm{CIADH}$ ha realizado una interpretación expansiva de los mismos ${ }^{3}$. Ello a la luz de lo dispuesto por la Convención de Viena sobre el Derecho de los Tratados, la que indica que las disposiciones de un tratado deben ser interpretadas a la luz de su "objeto y fin", de acuerdo a lo prescrito por su artículo $31^{4}$. En la medida que el "objeto y fin" de la Convención Americana es promover los derechos de las personas, la $\mathrm{CIADH}$ ha aplicado el principio de interpretación pro homine, el que le lleva a preferir aquella interpretación que «proporcione el mayor grado de protección a los seres humanos bajo su tutela». Esa visión ha movido a la Corte a efectuar una interpretación finalista del texto de la Convención, «lo cual requiere que los estados garanticen y respeten los derechos contenidos en esta de manera que sus salvaguardas sean prácticas y efectivas (effet utile)» ${ }^{6}$. Ello, en la práctica, lleva a la CIADH a preferir una interpretación que no excluya garantías no reconocidas expresamente en la Convención ${ }^{7}$.

Es en ese contexto que el artículo 29 letra c) de la Convención Americana adquiere relevancia para determinar la jurisdicción ratione materiae de la CIADH. El artículo 29 letra c) de la Convención Americana indica que la enumeración de derechos y libertades en la Convención no excluye "otros derechos y garantías que son inherentes al ser humano o que se derivan de la forma democrática representativa de gobierno». Lo cual, sumado al principio pro homine, justificarían que los derechos «deb[a] interpretarse de manera amplia, de modo que dicha interpretación se apoye tanto en el texto literal de esa norma como en su espíritu, y deb[a] ser apreciado de acuerdo con el artículo 29, inciso c) de la convención» ${ }^{8}$.

Este precepto es similar no solo a la novena enmienda de la Constitución norteamericana, sino a numerosas otras cláusulas de este tipo contenidas en constituciones latinoamericanas ${ }^{9}$, las cuales, a juicio de algunos autores, sirvieron de factor inspirador a la norma en comento ${ }^{10}$. En efecto, aquella norma sería una cláusula que permitiría, en principio, evitar el cierre del catálogo de derechos fundamentales contenido en la Convención ${ }^{11}$. Algunos han visto en esta norma la fuente directa de los derechos implícitos en la Convención, explicando que la disposición «permite comprender el efecto vinculante de otros derechos

\footnotetext{
2 Las Palmeras con Colombia (2000) párrafo 33. Véase también: Burgorgue-Larsen (2011) p. 64.

3 Pasqualucci (2013) pp. 12-14.

4 Burgorgue-Larsen \& Úbeda de Torres (2011) pp. 58-59.

5 BENJAMIN Y OTROS CON TRINIDAD Y TOBAGO (Objeciones preliminares) (2001) párrafo 70.

6 VARgas ARECO CON PARAGUay (2006) párrafo 85.

7 Pasqualucci (2012) p. 14; Harris (2004) p. 10.

8 BLAKE CON GUATEMALA (1998) párrafo 96.

9 Gros (2000) pp. 145-146. Para un análisis del caso chileno véase Aldunate (2008) pp. 345-347; Contreras (2011) y CANDia (2014).

10 Véase Gros (2000) pp. 169-170.

11 LEÓN (2010) pp. 280-281.
} 
que, aun cuando no fueron recogidos expresamente por los pactos internacionales (...) quedan implícitamente garantizados en virtud de la disposición analizada» ${ }^{12}$. De acuerdo a este criterio, el artículo 29 letra c) permitiría afirmar que dentro del sistema interamericano de Derechos Humanos existirían -al igual que en la Constitución norteamericana o que en otras constituciones latinoamericanas- tanto derechos enumerados expresamente en el catálogo de derechos, como derechos no-enumerados o implícitos en el catálogo contenido en la Convención ${ }^{13}$, lo que permitiría identificar al sistema interamericano de Derechos Humanos como «un todo que sobrepasa la mera letra de la ley» ${ }^{14}$.

En ese contexto, la formulación de dichos derechos, de acuerdo a la CIADH, representaría un acto de interpretación que no agregaría ningún contenido que ya no existiese en el texto del tratado. Ello permitiría a la Corte afirmar que sus actuaciones se mantienen dentro de los límites de su competencia establecidos en el artículo 62.3 de la Convención. En ese sentido, la CIADH parece referir que la producción de derechos implícitos no es el resultado de una labor creadora de Derecho, sino de una labor puramente interpretativa.

Uno de los factores referidos por la CIADH para justificar su labor como meramente interpretativa ha sido la conceptualización de la Convención Americana como un instrumento viviente. Por ejemplo, la Corte en Niños de la Calle (Villagrán Morales y otros) con Guatemala, ha indicado que tanto la Corte Interamericana, como la Corte Europea de Derechos Humanos: "han señalado que los tratados de derechos humanos son instrumentos vivos, cuya interpretación tiene que acompañar la evolución de los tiempos y las condiciones de vida actuales» ${ }^{15}$. Este es un punto relevante. Si la Convención es un instrumento viviente, entonces su texto no representa el límite principal para el accionar de la CIADH sino que con esta fórmula «se entiende la norma de ley no en las abstractas posibilidades interpretativas que descienden de los textos, sino la norma de ley tal como "vive" en la interpretación consolidada de los jueces» ${ }^{16}$.

\subsection{RECONOCIMIENTO Y PRÁCTICA DE LOS DERECHOS IMPLícitos}

En relación a la forma como la $\mathrm{CIADH}$ ha concebido la elaboración de derechos implícitos, es posible apreciar el siguiente procedimiento. Primero, la Corte afirma que los preceptos de la Convención deben ser interpretados en conformidad a los criterios expuestos en el apartado anterior. Luego, la Corte -en la mayoría de los casos- refiere una norma de la Convención cuyo texto es vago e indeterminado. Finalmente, la CIADH indica que dicha norma exige necesariamente la adopción de un cierto estándar. El contenido de dicho estándar es conceptualizado por la Corte como un derecho construido por la misma a partir de un método de deducción lógica, en el cual la demanda conceptual del derecho expresado en el texto de la Convención supera la frontera de lo meramente posible y asume carácter de lógicamente necesario. En virtud de este procedimiento es posible constatar dos

\footnotetext{
12 Nogueira (2007) p. 458.

13 Gros (2000) pp. 168-169.

14 Medina (2003) p. 6.

15 NiÑOS DE LA CALLE CON GUATEMala (1999) párrafo 193.

16 Zagrebelsky (2008) p. 333.
} 
consecuencias: el reconocimiento de derechos no contemplados en el texto y la incorporación indirecta de derechos y estándares de juicio provenientes de otros tratados internacionales de derechos humanos.

En cuanto al reconocimiento de derechos no contemplados en el texto de la Convención, uno de ellos es el derecho a la verdad y a la efectiva sanción penal. De acuerdo a la CIADH, dicho derecho impone al estado: (a) la obligación de determinar por vía judicial los hechos existentes detrás de las violaciones de derechos humanos ${ }^{17}$ y (b) aplicar una sanción penal a los responsables ${ }^{18}$. Ello aun cuando existieran amnistías o prescripciones que hicieran caducar la acción penal, las que deben ser dejadas sin efecto por parte de los mismos tribunales nacionales ${ }^{19}$. A pesar que en un primer momento la propia CIADH afirmó que el derecho a la verdad «es un derecho no existente en la Convención Americana» ${ }^{20}$, la Corte terminó posteriormente incluyendo el derecho a la verdad dentro del catálogo de derechos de la Convención, merced a una nueva interpretación de los artículos $8^{\circ}$ y 25 del tratado, operación realizada en conformidad al procedimiento deductivo señalado anteriormente.

Otro derecho implícito reconocido por la CIADH es el derecho comunal a la propiedad indígena. En Comunidad Mayagna (Sumo) Awas Tingni con Nicaragua, la Corte consideró que «el artículo 21 de la Convención protege el derecho a la propiedad en un sentido que comprende, entre otros, los derechos de los miembros de las comunidades indígenas en el marco de la propiedad comunal» ${ }^{21}$. Similar doctrina es reiterada unos pocos años después por la CIADH en el caso Comunidad Indígena Yakye Axa con Paraguay, donde se volverá a decir que «tanto la propiedad privada de los particulares como la propiedad comunitaria de los miembros de las comunidades indígenas tienen la protección convencional que les otorga el artículo 21 de la Convención Americana» ${ }^{22}$.

La incorporación del derecho a la propiedad indígena en el texto de la Convención fue realizada por la CIADH a través de una interpretación extensiva del artículo 21 del tratado, el que reconoce el derecho de las personas al «uso y goce de sus bienes» bajo el apartado de «derecho a la propiedad privada». A pesar de la relativa claridad del texto en cuestión, la Corte afirmó que este texto debía ser interpretado: (a) de forma autónoma -esto es, no condicionando el sentido y alcance de sus términos a aquel que las normas de Derecho interno le asignan-; (b) considerando que la Convención era un instrumento evolutivo y (c) evitando, en conformidad al artículo 29 letra b) de la Convención, cualquier interpretación de tipo restrictivo de la norma. A partir de lo anterior -y sin dar fundamentos adicionales- la CIADH entendió que el artículo 21 de la Convención necesariamente requería el reconocimiento del derecho a la propiedad comunal indígena, el cual no se encuentra específicamente señalado en el texto de la Convención Americana.

\footnotetext{
17 Almonacid AReLlano y otros con Chile (2006) párrafo 150.

18 Almonacid ARellano y otros con Chile (2006) párrafo 150.

19 Almonacid ARellano y otros con Chile (2006) párrafos 147-148.

20 Castillo PÁez con Perú (1997) párrafo 86.

21 Comunidad MaYagna (Sumo) Awas TingNi con NiCARAGUa (2001) párrafo 148.

22 Comunidad Indígena YAKYe AXa con PARAgUaY (2005) párrafo 143.
} 
Una particularidad aneja al proceso de derivación de derechos implícitos es la deducción de derechos a partir de otros derechos anteriormente deducidos. Por ejemplo, la CIADH a partir del reconocimiento de un derecho implícito, el derecho a la propiedad comunal indígena, ha deducido el derecho de las comunidades indígenas de acceder a «los recursos naturales ligados a su cultura que ahí se encuentren, así como [a] los elementos incorporales que se desprendan de ellos» ${ }^{23}$. En ese sentido, la CIADH ha señalado que el derecho a la propiedad de los pueblos indígenas se extendería también a aquellos recursos naturales ubicados dentro del territorio que habitan y que fuesen estrictamente necesarios para su sobrevivencia ${ }^{24}$. Por tanto, toda intervención estatal en el ejercicio de este derecho no puede amenazar la sobrevivencia de la forma de vida de la comunidad en cuestión ${ }^{25}$. Como es posible apreciar, ninguna de estas definiciones de política indígena se encuentra expresamente referidas por el texto de la Convención. A pesar de ello, la Corte los ha igualmente incluido en el catálogo de derechos del tratado.

Con respecto a la incorporación indirecta de derechos y estándares de juicio provenientes de otros tratados internacionales de derechos humanos, sirva de ejemplo el tratamiento que la Corte ha dado al derecho a la identidad. El texto de la Convención Americana reconoce en su artículo 18 el derecho de toda persona a acceder a un nombre propio y a los apellidos de los padres o al de uno de ellos. Sin embargo, la Convención no reconoce un derecho específico de acceso a la verdad en torno a la paternidad biológica de cada persona. Luego, el texto del tratado no incluye el reconocimiento del derecho a la identidad. Esto lo reconoció la propia CIADH al afirmar que el derecho a la identidad no era uno de aquellos enumerados por la Convención Americana ${ }^{26}$.

A pesar de lo anterior, la CIADH igualmente lo incorporó tácitamente al texto del tratado. Ello lo hizo a través de la interpretación que efectuó de los artículos 18 y 19 de la Convención Americana a la luz del artículo $8^{\circ}$ de la Convención de los Derechos del Niño, el que reconoce expresamente el derecho de los niños y adolescentes a «preservar su identidad $\aleph^{27}$. En ese sentido, de acuerdo a la Corte, la norma mencionada debía ser comprendida dentro del artículo 19 de la Convención Americana, el que indica que todo niño tiene derecho a "las medidas de protección" de parte de la familia, la sociedad y el Estado. La CIADH, por tanto, supuso que la búsqueda de esa verdad en torno al origen biológico era necesariamente un tipo de "medida de protección" estatal y, a través de esta vía, incorporó -en la práctica- la norma a la Convención como derecho autónomo.

Teniendo en cuenta estas dos consecuencias, cabe descartar de plano la polemicidad de la aplicación de otros tratados internacionales por parte de la CIADH si estos han sido suscritos por los Estados que son parte de la controversia y si se ha otorgado competencia a la Corte para aplicarlos. Sin embargo, la incorporación de derechos a la Convención por vía judicial no posee una salida igual de pacífica. Los análisis de contexto con los que la

\footnotetext{
23 Comunidad INDígena YAKYe AXa CON PARAGUay (2005) párrafo 137.

24 Pueblo de Saramaka con SuRIName (2007) párrafo 118.

25 Pueblo de Saramaka con Suriname (2007) párrafo 129.

26 JUAN GELMAN CON URUGUAY (2011) párrafo 122.

27 JUAN GELMAN CON URUGUAY (2011) párrafo 122.
} 
doctrina ha explicado el procedimiento particular de deducción interpretativa utilizado por la Corte en estos casos han sido útiles, tanto para entender el panorama histórico-político bajo el cual actúa la CIADH, como para evidenciar que esta interpretación ha reñido con decisiones soberanas de estados que han ratificado la Convención ${ }^{28}$. A pesar de esa utilidad, los análisis doctrinarios de esta naturaleza no permiten dar cuenta de las razones de fondo que explican esta práctica de la Corte y, con ello, no son capaces de solucionar los aspectos controversiales de la misma. Es por ello que hace falta comprender la real naturaleza de los derechos implícitos y, a través de aquello, analizar los límites de la facultad interpretativa de la Corte.

\section{LOS DERECHOS IMPLÍCITOS COMO EXTENSIÓN DE LA FACULTAD INTERPRETATIVA DE LA CORTE}

Esta sección del artículo busca examinar y situar la práctica generadora de derechos implícitos de la CIADH a la luz de la discusión doctrinaria en torno a la interpretación y la construcción normativa por parte de los tribunales. Dicha contextualización permitirá entender la actuación de la CIADH en una perspectiva teórica.

\subsection{LOS DERECHOS IMPLÍCITOS: ¿INTERPRETACIÓN O CREACIÓN JUDICIAL?}

La CIADH siempre ha afirmado que la formulación de derechos implícitos es un acto de interpretación, pero nunca de creación judicial. Ahora bien, esto no es algo nuevo. Al mirar las distintas experiencias en el Derecho Comparado es fácil apreciar que en todos aquellos procesos en los cuales las cortes han generado derechos implícitos a partir de declaraciones de derechos, ellas lo han hecho rechazando la idea de que están creando Derecho. En efecto, en el contexto del Derecho interno de los estados, las cortes reforman la Constitución alegando "no estar haciéndolo» ${ }^{29}$. En ese sentido, cuando las cortes constitucionales crean derechos, ellas evitan utilizar esta terminología, indicando que solo «han descubierto dichos derechos en el texto de la Constitución, sin agregar nada a la misma» ${ }^{30}$.

Conforme a esto último, MaLARINo críticamente señala que la Corte «con frecuencia decide sin un claro apoyo en la Convención» ${ }^{31}$ y las pocas veces que lo hace, «se refiere a la Convención Americana como un 'instrumento viviente' que debe interpretarse de manera 'evolutiva', 'progresiva' o 'dinámica'»32.

Estas observaciones, sin embargo, no son concluyentes por sí solas. En efecto, el solo hecho de evidenciar una práctica o de explicarla en el contexto histórico-social latinoamericano no es suficiente para su afirmar su legitimidad. En ese sentido, se echa en menos en la doctrina un análisis sustancial que permita distinguir cuándo estamos en presencia de un ejercicio hermenéutico ejercido en conformidad a las facultades interpretativas de la Corte

\footnotetext{
28 Véase especialmente el realizado en BURGORGUE-LARSEN (2014).

29 Goldsworthy (2011) p. 56.

30 Goldsworthy (2011) p. 56.

31 Malarino (2010) p. 27.

32 Malarino (2010) p. 27.
} 
y cuándo en presencia de uno que excede dichas facultades y, de paso, extiende su competencia ratione materiae. Ello provendrá, necesariamente, de un estudio previo de la doctrina de los derechos implícitos.

Antes de aquello, sin embargo, es necesario hacer una distinción inicial y detenernos brevemente en la idea de creación judicial del derecho, dado que tal como lo afirma CARRIÓ: «El reconocimiento de que los jueces pueden y suelen crear derecho se ha esparcido por todas partes» ${ }^{33}$. A raíz de esto corresponde establecer hasta qué punto el reconocimiento de esta facultad generadora se condice con su función interpretativa, correspondencia que se observa en la generación de reglas jurídicas de situaciones particulares donde la norma a aplicar carece de la especificidad necesaria para resolver un caso. En dichas situaciones, las cortes deben efectuar un acto de determinatio judicial que permita la implementación de la norma al caso concreto ${ }^{34}$. En términos generales, podríamos definir la determinatio judicial como el acto por medio del cual un juez asigna un determinado sentido semántico a una norma legal que debe aplicar y cuyo contenido es tan indeterminado que su solo texto y la aplicación de las reglas ordinarias de interpretación no son capaces de resolver el caso por sí mismas ${ }^{35}$.

Esto que vale para las reglas jurídicas en general es aún más necesario tratándose de los textos de las convenciones de derechos humanos, caracterizados por tener una densidad normativa de escasa consistencia en la mayoría de su articulado. Eso explica que, en su aplicación, los jueces de las cortes internacionales de derechos humanos deban no solo considerar el material jurídico relevante que pueda existir para desentrañar el sentido y alcance de la norma en cuestión, sino también "superar las indeterminaciones» ${ }^{36}$ del texto con el propósito de subsumir, posteriormente, el caso concreto dentro de la especificación judicial de la norma en cuestión.

La indeterminación a la cual están sujetas la mayoría de las normas de las convenciones internacionales de derechos humanos -e.g., la Convención Americana- puede ser de tipo semántica, sintáctica, pragmática o lógica. Para estos efectos consideremos únicamente los casos de indeterminación semántica, que son aquellos que más preocupan tanto al Derecho Constitucional como al Derecho Internacional de los Derechos Humanos. Una norma es semánticamente indeterminada en la medida que represente instancias de ambigüedad o vaguedad. En este sentido, una norma es ambigua en la medida que los términos en análisis tengan más de un sentido. Por tanto, la ambigüedad referirá siempre a «la multiplicidad de sentido» ${ }^{37}$ que puedan naturalmente tener ciertas palabras. Dicha ambigüedad podrá ser resuelta, en la mayoría de los casos, por medio de la consideración del contexto específico dentro del cual se encuentran las expresiones lingüísticas.

Cosa distinta ocurre con expresiones vagas, tales como igualdad, representatividad o expresión. En la mayoría de aquellos casos comprendemos el contexto en el cual dichas

\footnotetext{
33 CARrió (1989) p. 35.

34 FinNis (2011a) p. 284.

35 WALDRON (2010) p. 6.

36 Nino (2000) p. 85.

37 Sollum (2010) p. 97.
} 
palabras son utilizadas. Así, por ejemplo, sabemos que cuando hablamos de igualdad, hablamos de cierto tratamiento similar entre personas que se encuentran en una misma situación. Sin embargo, la expresión es vaga en el sentido que existen casos respecto de los cuales el concepto puede o no ser aplicado ${ }^{38}$. Esto es, la expresión dice relación con un continuo respecto del cual no existe plena claridad acerca del punto en el que se inicia y en el punto en que termina ${ }^{39}$. El Derecho Internacional de los Derechos Humanos, así como el Derecho Constitucional, está lleno de problemas asociados a la vaguedad de su propia terminología y este es el contexto en el cual los jueces constitucionales e internacionales deben moverse en buena parte de los casos que les corresponde decidir.

Esta vaguedad de textura abierta afecta a todas las normas jurídicas en la medida que las mismas se construyen a partir de lenguajes naturales que tratan de establecer generalizaciones respecto de clases de personas, actos, cosas y circunstancias ${ }^{40}$. En la medida que el uso de las palabras generalizadoras muchas veces no es capaz de comprender dentro de sí todos los posibles particulares que pueden emerger bajo su descripción, el alcance de aquellas es limitado ${ }^{41}$. Ello es lo que precisamente ocurre con conceptos abstractos de uso general como igualdad, expresión, debido proceso, expropiación, justa remuneración, etc. Esa vaguedad no solo se debe a la textura abierta del lenguaje que es utilizado para redactar las convenciones internacionales de derechos humanos, sino también a la relativa indeterminación de propósitos que motiva su promulgación. En efecto, los estados que trabajan en la preparación del texto de las convenciones no tienen la capacidad para prever todas las circunstancias a las cuales la norma será aplicada. Por tanto, es perfectamente posible que surjan circunstancias distintas y existan dudas más que razonables acerca de la aplicación de la norma al caso concreto ${ }^{42}$.

Sin embargo, esa indeterminación no es absoluta. Si así fuese, entonces las palabras utilizadas por las convenciones internacionales de derechos humanos no serían capaces de comunicar nada a sus destinatarios. Por el contrario, los términos de textura abierta tienen instancias «en las cuales no existen dudas respecto de su aplicación» ${ }^{43}$. Estos son los denominados casos típicos o centrales de la aplicación de la norma. Ellos permiten incluir o excluir su aplicación de forma más o menos clara. Sin embargo, estos casos típicos coexisten con casos de "penumbra", en los cuales no es claro si la norma en cuestión -e.g., la garantía que protege la libertad de expresión- aplica o no ${ }^{44}$. Ello en la medida que el caso al cual la norma se pretende aplicar tiene ciertos elementos del caso típico, pero posee, además, otros distintos. La vaguedad, precisamente, «se pone de manifiesto en el caso atípico» ${ }^{45}$. En efecto, es el caso atípico el que nos muestra que la norma en análisis no puede cubrir con suficiente claridad todos los casos a los cuales podría ser aplicada. En ese sentido, a lo más

38 Sollum (2010) p. 98.

39 Nino (2000) p. 90.

${ }^{40}$ Hart (1994) p. 124.

${ }^{41}$ Hart (1994) p. 126.

${ }^{42}$ Hart (1994) pp. 128-129.

${ }^{43}$ Hart (1958) p. 607.

${ }^{44}$ Hart (1958) p. 607.

45 Carrió (1994) p. 55. 
que puede aspirar la norma vaga es a «acotar un campo de límites imprecisos, dentro de los cuales podemos señalar ejemplos claros [de aplicación]» ${ }^{46}$ Sin embargo, definir una línea conceptual que permita distinguir de forma clara entre un caso típico y uno atípico es un ejercicio sumamente complejo ${ }^{47}$.

Los problemas de penumbra son una constante en la aplicación de las declaraciones de derechos contenidas en las convenciones internacionales. Ello debido a las razones anteriormente mencionadas y, en muchos casos, a la voluntad misma de los Estados que, por razones políticas, prefirieron evitar regular de forma específica casos concretos mediante una regla generando, en cambio, un estándar amplio y textualmente indeterminado ${ }^{48}$. La problemática de los derechos implícitos aparece precisamente en medio de esa penumbra que rodea la aplicación de normas de derechos humanos.

Anteriormente se ha señalado que los jueces internacionales deben efectuar juicios normativos para resolver casos atípicos de derechos humanos, esto es, casos que no encuentran una respuesta específica en el texto de las convenciones internacionales de derechos humanos o en la práctica generalizada de los Estados y las cortes. Esto es, casos que se encuentran, en general, ubicados en la zona de penumbra. En la mayoría de los casos, esa resolución se relaciona con la aplicación de una norma semánticamente indeterminada a un caso concreto.

La pregunta que surge en ese contexto es si la decisión del juez que resuelve ese caso requiere de una mera interpretación del precepto indeterminado o bien si la resolución de ese caso involucra una acción creativa que excede el texto normativo ofrecido por el constituyente (tratándose de jurisdicciones constitucionales) o los Estados (tratándose de tribunales internacionales de derechos humanos). En este sentido, autores tales como WHITTINGTON $^{49}$, BARNETT $^{50}$ y SOLLUM ${ }^{51}$ han señalado que se hace necesario distinguir entre dos esferas de acción del juez: aquella que se refiere a la labor de interpretación y aquella que dice relación con la de construcción. Así, por ejemplo, de acuerdo a Sollum, la labor de interpretación está íntimamente vinculada a la determinación del sentido y alcance lingüistico de las palabras y oraciones contenidas en el texto de la norma indeterminada ${ }^{52}$. Mediante la interpretación, uno de los problemas que los jueces pueden resolver es el de la ambigüedad, el que dice relación con la existencia de más dos significados posibles para el texto de la norma. En ese sentido, el contexto del caso permitiría al juez identificar cuál de esos significados es el más propio para la norma cuyo significado es objeto de la disputa ${ }^{53}$.

Sin embargo, en los casos de vaguedad, la interpretación no es suficiente para resolver un caso concreto. Tratándose de normas indeterminadas semánticamente, el texto no ofrece por sí mismo una solución específica a los casos concretos a los cuales debe ser

46 Carrió (1994) p. 33.

47 Atria (2001) pp. 73-74.

${ }_{48}$ NinO (2000) p. 89.

49 Whittington (1999) pp. 5-16.

50 BarnetT (2004) pp. 118-130.

${ }^{51}$ Sollum (2010) pp. 95-118.

52 Sollum (2010) p. 102.

53 Sollum (2010) p. 102. 
aplicado, aun cuando el sentido y alcance lingüístico de la norma sea relativamente claro ${ }^{54}$. En esos casos, el juez debe resolver derechamente si la situación que es objeto del caso se encuentra dentro del continuo representado por la misma ${ }^{55}$.

En esos casos, las cortes deben adoptar alguna regla para derechamente solucionar el caso concreto. Esto es denominado construcción ${ }^{56}$. La construcción adoptada por el juez para resolver un caso en circunstancias en las cuales el texto no ofrece orientación alguna para decidir, supone que el juez adopta ciertas premisas valorativas que van más allá del significado literal del texto ${ }^{57}$. En ese sentido, la justificación última de la construcción generada por el juez es de carácter normativo y no puramente interpretativo. En efecto, tal como HaRT lo señala, la decisión representará una opción normativa del juez, posible entre muchas razonables, pero no completamente necesaria ${ }^{58}$.

\subsection{LOS DERECHOS IMPLÍCITOS COMO ACTO DE CREACIÓN JUDICIAL}

En el contexto descrito en el apartado anterior, la definición de derechos implícitos es un acto de producción normativa, esto es, de creación de Derecho. Esta realidad ha sido asumida por parte de la doctrina. Por ejemplo, Burgorgue-Larsen afirma que el reconocimiento de derechos implícitos en la Convención «[se] trata, ni más ni menos, que de [de una actuación destinada a] "crear" nuevos derechos»" en la medida que los jueces que toman decisiones en el campo del Derecho Internacional de los Derechos Humanos "gozan de una considerable latitud para ejercer sus funciones creativamente ${ }^{60}$. En ese contexto, la estrategia adoptada por la CIADH «es particularmente astuta» ${ }^{61}$ al vincular "sistemáticamente estos nuevos derechos a uno o más fundamentos jurídicos preexistentes en el seno de la Convención Americana» ${ }^{62}$. Efectivamente, la estrategia es astuta, por cuanto permite a la Corte crear e incorporar nuevos derechos al tratado arguyendo la interpretación del mismo.

Esa estrategia es observable al estudiar el proceso de creación del derecho de propiedad comunal indígena. El texto del artículo 21 de la Convención era muy escueto (garantizaba el "uso y goce de [los] bienes") y los jueces debían determinar si dentro del estándar ofrecido por la norma se protegía no solo la propiedad privada sino también la comunal indígena, aun cuando del texto y la historia de la norma se podía entender que no. De hecho, el numeral primero de la norma en cuestión afirma que "toda persona tiene derecho al uso y goce de sus bienes». Asimismo, si bien durante la discusión de la norma en cuestión -según consta en los trabajos preparatorios de la Convención- se eliminó la expresión "propiedad

${ }^{54}$ Sollum (2010) p. 104.

55 Sollum (2010) pp. 103-104.

56 Sollum (2010) p. 103.

57 Sollum (2010) p. 104.

58 HART (1994) p. 127.

59 Burgorgue-Larsen (2014) p. 125.

${ }^{60}$ Medina (2013) p. 651

${ }^{61}$ Burgorgue-Larsen (2014) p. 125.

${ }_{62}$ Burgorgue-Larsen (2014) p. 125. 
privada”, el único fin de aquello fue simplemente evitar que la norma fuese invocada para posponer la realización de procesos de reforma agraria en el continente ${ }^{63}$.

Aun cuando existieran elementos de juicio histórico a considerar, la Corte decidió expandir el continuo protegido por el artículo 21 de la Convención Americana. Ello no fue un acto de mera interpretación cuyo objeto fue desentrañar el sentido y alcance de la expresión "uso y goce de bienes" dentro de un cierto contexto fáctico; por el contrario, la formulación del derecho implícito a la propiedad comunal indígena representó un acto de construcción normativa orientada por criterios valóricos que excedían el marco del texto y la historia de la disposición. Dichos criterios aludían al "deber ser" de la norma. En ese sentido, la construcción normativa de la CIADH constituye una implementación posible (lo que podría incluso llegar a ser discutible a la luz de lo mencionado anteriormente) pero no necesaria del artículo 21.

Desde la perspectiva de las obligaciones generadas para los Estados a partir de los derechos implícitos, es necesario señalar que la creatividad judicial produce una serie de tensiones dentro del sistema interamericano. Efectivamente, la sola existencia de normas vagas o ambiguas en la Convención no debe leerse como una invitación al ejercicio de una discrecionalidad absoluta por parte del juez interamericano. De aceptar esa visión, la CIADH tendría gozaría de un poder que le permitiría, por la vía de la creación de derechos, imponer a los Estados partes de la Convención una serie de obligaciones respecto de las cuales los Estados no manifestaron su consentimiento al tiempo de la ratificación del tratado.

Desde esa perspectiva, aceptar el carácter legislativo de las decisiones judiciales que generan derechos implícitos exige también determinar un criterio de justificación para las mismas. Para quienes promueven y validan esta actuación normativa de la CIADH, el criterio de justificación primigenio sería de naturaleza sociopolítica (la necesidad de implementar de forma efectiva los derechos en un contexto histórico y social de vulneración). Ello dado la ausencia de una fuente legal clara que asigne ese poder creador a la Corte. Por el contrario, una posición que se oponga a la práctica de la incorporación tácita por vía judicial de nuevos derechos deberá adoptar un criterio de justificación cuya naturaleza será prevalentemente jurídica. Esto es, que la CIADH no podría encontrar fundamento a su práctica creadora en las normas de la Convención.

Esta contraposición entre lo político y lo jurídico puede no tener solución sino en la medida que ambas posturas, que invocan criterios de justificación de carácter diverso, puedan dialogar dentro de un lenguaje común que ambas partes acepten. Ese lenguaje común es, precisamente, ofrecido por la noción de estado de Derecho. La misma será desarrollada en el siguiente apartado.

\subsection{Noción de Estado de Derecho en el Sistema Interamericano y sus CONSECUENCIAS EN LA INTERPRETACIÓN DE LA CORTE \\ Que la noción de Estado de Derecho pueda servir de fundamento tanto para justifi-} car la actitud creadora de derechos implícitos por parte de la CIADH como aquella postura que se opone a aquella supone: (a) que cada postura en conflicto refiere a la noción en co-

63 Organización de Estados Americanos (1969) p. 239. 
mento de forma idéntica a la alternativa y (b) que existe la posibilidad de que la conclusión final no solo se reduzca a un mero tomar partido entre dos posturas irreconciliables, sino que se pueda establecer que una de esas dos posturas concluye de forma correcta. Ello dado que se dispone de una premisa mayor -la noción de estado de Derecho- que sirve de referencia a la premisa menor ofrecida por cada una de las posiciones en disputa.

En términos generales, la noción de estado de Derecho exige que la actividad estatal se sujete a una serie de requisitos al momento de producir y aplicar normas. En ese sentido, el estado de Derecho es "una expresión de legitimidad política»" ${ }^{64}$ en la medida que limita la discrecionalidad de la autoridad estatal en sus actuaciones. Simultáneamente, el cumplimiento por parte de la autoridad estatal de las demandas planteadas por el estado de Derecho para la producción y aplicación de normas es señal de que "el "sistema jurídico" está funcionando bien ${ }^{65}$, y, por tanto, la noción es también criterio de legitimidad jurídica. Es precisamente esa doble legitimidad, aceptada por la generalidad de los operadores jurídicos, la que permite efectuar un análisis de las posiciones en comento a la luz de la noción de estado de Derecho.

Este artículo no pretende enumerar y describir cada uno de los requisitos cuyo cumplimiento demanda el estado de Derecho ${ }^{66}$. En ese sentido, se referirán únicamente aquellos requisitos vinculados al presente trabajo, los que dicen relación con los límites que se imponen a la potestad judicial para crear nuevos derechos como resultado de un proceso de adjudicación internacional.

Antes de entrar en esas condiciones particulares que legitimarían o restarían legitimidad a ese proceso, hace falta considerar la aplicabilidad de la noción de estado de Derecho al ámbito de las relaciones entre los Estados y las cortes internacionales.

En principio, pareciera que las obligaciones engendradas por la noción de estado Derecho afectan solo a las autoridades de los Estados dentro de sus propias jurisdicciones nacionales. Sin embargo, ello no es así. En efecto, tal como WALDRON lo ha señalado, los principios que caracterizan el estado de Derecho también demandan que los Estados sean respetuosos del Derecho, aun cuando se trate de actuaciones de los mismos en la esfera internacional ${ }^{67}$. En ese mismo sentido, la sujeción al estado de Derecho por parte de los Estados en sus relaciones internacionales promueve no solo la paz entre los mismos, sino «también la justicia, en un contexto donde ella es entendida, en primer lugar y de forma principalísima, pero no excluyente, como la promoción y realización de los derechos humanos» ${ }^{68}$. En ese sentido, las limitaciones que el estado de Derecho impone a los Estados en el ámbito interno de su jurisdicción no son menores que aquellas que el mismo estado de Derecho exige en la esfera de lo internacional ${ }^{69}$.

\footnotetext{
64 Pérez (1991) p. 59.

65 Finnis (2011a) p. 270.

66 Condiciones en las que se detienen autores como Joseph RaZ y John Finnis. Véanse: Raz (2002) pp. 20-25, FINNIS (2011a) pp. 270-271.

67 Waldron (2006) p. 21.

68 Buchanan (2010) p. 89.

69 WaLdRon (2006) p. 21-25.
} 
Ahora bien, la noción de estado de Derecho supone la existencia de una relación de reciprocidad entre quienes producen y aplican el Derecho y quienes lo obedecen ${ }^{70}$. En el ámbito interno, esto significa que el Estado tiene un título moral para exigir el cumplimiento del Derecho a sus ciudadanos, en la medida que el mismo Estado se encuentra sujeto a ese Derecho ${ }^{71}$. Esa reciprocidad también aplicaría a la relación existente entre los Estados y las cortes internacionales. Por tanto, tal como los Estados se someten a las decisiones de los tribunales a quienes confieren jurisdicción ${ }^{72}$, así también las cortes internacionales deben someterse en su actividad interpretativa o creadora al Derecho producido por los propios Estados. En ese contexto, y tal como BESSON afirma, «los procesos de creación de Derecho Internacional deben estar constituidos de forma tal que satisfagan algunas de las exigencias asociadas con el estado de Derecho en el ámbito internacional, particularmente las exigencias de claridad, publicidad, certeza, igualdad, transparencia e imparcialidad ${ }^{73}$. Estas demandas son perfectamente exigibles a las cortes internacionales de derechos humanos, especialmente al momento de aplicar normas semánticamente indeterminadas. Ello en la medida que dichas cortes gozan en esos ámbitos de mayores grados de discrecionalidad.

En relación a la noción de estado de Derecho, la CIADH ha reconocido que aquel está «configurado por una serie de reglas que definen el ámbito del poder y lo subordinan a los derechos y atributos inherentes a la persona humana ${ }^{74}$. En ese sentido, la Corte ha explorado la noción de estado de Derecho como límite a la discrecionalidad del poder, entendiendo que «en una sociedad democrática los derechos y libertades inherentes a la persona, sus garantías y el estado de Derecho constituyen una tríada, cada uno de cuyos componentes se define, completa y adquiere sentido en función de los otros» ${ }^{75}$. Es por ello que la CIADH ha manifestado que «el principio de legalidad, las instituciones democráticas y el Estado de Derecho son inseparables» ${ }^{76}$.

En ese contexto, la idea de legalidad promovida por la Corte se entiende en el sentido de limitación del poder; así, la suspensión de garantías autorizada por el artículo 27 de la Convención «no significa (...) que [ella] comporte la suspensión temporal del estado de Derecho o que autorice a los gobernantes a apartar su conducta de la legalidad a la que en todo momento deben ceñirse ${ }^{77}$. Por otro lado, la CIADH ha reforzado esta idea de límite en relación a la ejecución de las sentencias de los tribunales, señalando que en todo sistema jurídico fundado en la noción de estado de Derecho «todas las autoridades públicas, dentro del marco de su competencia, deben atender las decisiones judiciales, así como dar impulso

\footnotetext{
70 Fuller (1969) p. 39.

71 Fuller (1969) p. 39.

72 Ayala (2007) p. 133.

73 BESSON (2012) p. 172.

74 Fix-Zamudio (2011) p. II.

5 OPINIÓN CONSULTIVA OC-8/87 "EL HÁBEAS CORPUS BAJO SUSPENSIÓN DE GARANTIAAs", párrafo 26.

76 OPINión CONSUltiva OC-6/86 "LA EXPRESIÓN LEYES EN EL ARTÍCULO 30 dE LA CONVENCIÓN AMERICANA SOBRE DERECHOS HUMANOS", párrafo 32.

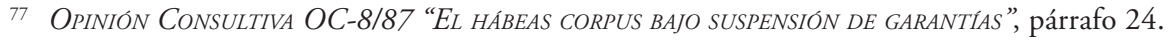


y ejecución a las mismas sin obstaculizar el sentido y alcance de la decisión ni retrasar indebidamente su ejecución ${ }^{78}$.

En relación a lo anterior, reviste particular interés para este trabajo el énfasis que pone la CIADH en que el estado de Derecho tiene una conexión directa con la idea de legalidad, entendida esta como limitación al ejercicio del poder ${ }^{79}$. La Corte ha aplicado, fundamentalmente, esta idea a la actuación de los Estados. Sin embargo, la misma puede aplicarse a la propia $\mathrm{CIADH}$, en la medida que se crea que la noción de estado de Derecho es aplicable dentro de las fronteras del Derecho Internacional de los Derechos Humanos. En ese contexto, la infracción de esa legalidad, por parte de los Estados o de la Corte, implicaría un atentado contra la noción de estado de Derecho que la propia CIADH promueve. Ahora bien, esa legalidad, asociada a la noción de estado de Derecho, supone que la estructura jurídica llamada a crear y aplicar el Derecho se encuentra limitada. Esa limitación, en la esfera técnica, implica diversas exigencias.

En primer lugar, la idea de legalidad demanda que las distintas formas de Derecho «deb[a]n interpretarse o aplicarse de acuerdo con métodos interpretativos uniformes, respetuosos de la forma de expresión y del contenido del tipo de Derecho en cuestión» ${ }^{80}$. Por tanto, la naturaleza del Derecho aplicar por un adjudicador tiene relevancia al momento de interpretar o construir una norma en relación a un caso concreto. Así, si el carácter del Derecho a aplicar tiene carácter contractual, el adjudicador -respetando la voluntad de las partes que le confieren la potestad para actuar- debe actuar de forma tal que su obrar se conforme a las expectativas que las mismas partes tenían al momento de conferirle esa autoridad. Por tanto, «si las partes desearon y esperaron una interpretación más 'literal' que aquella que el propio juez preferiría, él debería sentirse obligado a adoptar una aproximación interpretativa que incluso podría considerar como no óptima» ${ }^{81}$.

Esta idea de FULLER es relevante a la hora de considerar la aproximación interpretativa o creativa que la CIADH debe adoptar respecto del texto de la Convención Americana. En efecto, de acuerdo al artículo 62.3 del tratado, la Convención autoriza a la Corte a conocer de aquellos casos en que «los Estados partes (...) hayan reconocido o reconozcan dicha competencia, ora por declaración especial, como se indica en los incisos anteriores, ora por convención especial». Por tanto, la jurisdicción que ejerce la CIADH es de naturaleza evidentemente contractual. En ese contexto, una correcta adjudicación por parte de la Corte obliga a los jueces a tener una aproximación al menos prudente respecto del texto que los Estados le ofrecen para interpretar y aplicar, por más general que este sea.

Por tanto, si la CIADH pretende actuar de forma coherente con el papel esencial que la misma reconoce a la idea de legalidad, entonces la Corte debe ceñirse lo más posible a la literalidad del tratado. Ello en la medida que solo de esa forma se evita que los Estados sean condenados por el incumplimiento de obligaciones que los mismos no suscribieron ni ratifi-

\footnotetext{
78 FURLAN Y FAMILIARES CON ARGENTINA (2012) párrafo 211.

79 Para una lectura de la legalidad como limitación del poder en el ámbito penal, véase: García y MoraleS (2011) pp. 199-202.

80 Summers (2002) p. 40. Énfasis añadido.

81 Fuller (1978) p. 393.
} 
caron al momento de celebrar el tratado. Solo una aproximación de ese tipo es respetuosa de las expectativas que las partes tenían al momento de otorgar jurisdicción a la Corte.

Vinculado con la idea de legalidad, está también la exigencia de que los cambios en el Derecho «deben llevarse a cabo mediante procedimientos apropiados, por instituciones, autoridades o personas debidamente autorizadas para ello» ${ }^{82}$. Esto supone que esos procedimientos preexisten a la decisión del adjudicador y, por tanto, lo limitan. Ello porque los procedimientos mal podrían encontrarse en una sentencia judicial que requiere, precisamente, de aquellos medios para su propio funcionamiento. Por tanto, los mecanismos de cambio del Derecho exigen, de acuerdo a SuMMERs, tener forma escrita y ser promulgados, publicados, o, de otro modo, ser puestos en conocimiento de sus destinatarios ${ }^{83}$. En consecuencia, la Convención Americana contempla procedimientos de reforma de la misma, reconociendo en su artículo 31 que existe la posibilidad de que otros derechos y libertades sean incluidos en el "régimen de protección de esta Convención". Sin embargo, esa incorporación debe ser efectuada "de acuerdo a los procedimientos establecidos en los artículos 76 y 77 ” de la misma Convención Americana.

También la legalidad exige que «las normas y sus cambios deb[a]n ser generalmente prospectivas y no retroactivas» ${ }^{84}$. Tratándose de normas de Derecho Internacional, las mismas imponen obligaciones a los Estados, obligaciones cuya fuente principal se encuentra en el acuerdo de los propios Estados. En el contexto del sistema interamericano, la legalidad exige que la $\mathrm{CIADH}$ no condene a los Estados partes por la infracción de obligaciones no consentidas por los mismos al tiempo de la ratificación de la Convención.

Por último, en relación al respeto por las instituciones democráticas nacionales, este está íntimamente vinculado a la idea de legalidad. En efecto, «el Estado está obligado a desarrollar en su legislación aquellos derechos que en su formulación internacional carecen de la precisión necesaria para que puedan ser aplicados por los órganos del Estado» ${ }^{85}$. Dicha función debe ser asumida, esencialmente, por «los órganos legislativos constitucionalmente previstos y democráticamente elegidos» dentro de cada Estado ${ }^{86}$. Ello porque «a través de[1] [debate legislativo] (...) se permite a las minorías expresar su inconformidad, proponer iniciativas distintas, participar en la formación de la voluntad política o influir sobre la opinión pública para evitar que la mayoría actúe arbitrariamente» ${ }^{87}$. Ello, la propia CIADH reconoce, "representa un obstáculo importante para el ejercicio arbitrario del poder ${ }^{88}$. Desde esa perspectiva, el procedimiento legislativo nacional sirve un propósito vinculado

\footnotetext{
82 Summers (2002) p. 40.

83 Summers (2002) p. 39.

84 Summers (2002) p. 39.

85 Medina y Nash (2011) p. 14. Para una explicación teórica, véase: Yowell (2012) p. 505.

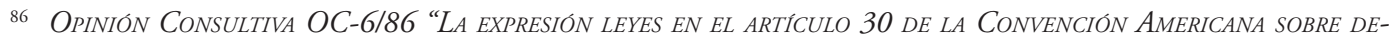
RECHOS HUMANOS”, párrafo 38.

87 Opinión Consultiva OC-6/86 "LA EXPREsión LEYES EN EL ARTíCULO 30 dE LA CONVENCIÓN AMERICANA SOBRE DERECHOS HUMANOS", párrafo 22.

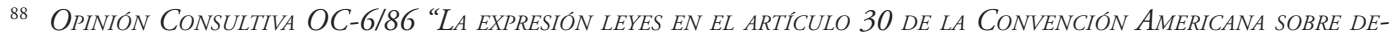
RECHOS HUMANOS”, párrafo 22.
} 
directamente con la noción de estado de Derecho: la limitación del poder, sea este ejercido por órganos de naturaleza ejecutiva, legislativa o judicial ${ }^{89}$.

Frente a los puntos anteriormente expuestos, si la CIADH busca ser coherente con su propia aproximación al estado de Derecho, es necesario que ella se someta tanto a las demandas exigidas por el principio de legalidad como a aquellas que provienen del respeto de las instituciones de la democracia representativa. En ese sentido, la juridicidad del Derecho Internacional de los Derechos Humanos solo podrá consolidarse si «los procesos de producción del Derecho están organizados de forma tal que reflejan los valores inherentes al estado de Derecho (...)» ${ }^{90}$.

La evaluación de la sujeción de la CIADH a los requerimientos del estado de Derecho tiene un sabor de dulce y agraz. De dulce, en la medida que la Corte ha sido, efectivamente, un baluarte de la defensa de la juridicidad en el continente en muchísimas ocasiones. Valga, por ejemplo, recordar el comportamiento de la CIADH frente a las violaciones masivas de derechos humanos y a los esfuerzos dictatoriales del chavismo venezolano. Pero también esa sujeción tiene algo de agraz, porque la CIADH en muchas ocasiones parece no sentirse vinculada por el carácter contractual de la jurisdicción que ejerce. Precisamente, cuando la Corte crea e incorpora nuevos derechos a la Convención a través del reconocimiento de derechos implícitos, lo hace (a) a través de mecanismos no previstos para ello; (b) vulnerando la autoridad conferida por los Estados y, por tanto, actuando ultra vires; e (c) imponiendo obligaciones sobrevinientes a los propios Estados. De la misma forma, la $\mathrm{CIADH}$ ha incorporado derechos a la Convención incluso en contra de la voluntad popular mayoritaria de un país ${ }^{91}$.

Visto que la creación de derechos implícitos no se corresponde plenamente con el ideal de estado de Derecho que la propia CIADH promueve, en la medida que dicha creación implica la vulneración de la idea de legalidad que la Corte plantea defender a nivel nacional, la última parte del trabajo ilustrará acerca de cómo la solución a esta problemática se encuentra dentro del propio sistema interamericano. En efecto, el mismo sistema posee elementos que, simultáneamente, (a) limitan la actuación judicial, (b) permiten la expansión de los derechos sujetos a la protección de la CIADH y (c) hacen, por tanto, prescindible la labor creadora de derechos implícitos por parte de la Corte.

\section{FACTORES QUE LIMITAN LA DISCRECIONALIDAD DE LA CIADH PARA CREAR DERECHOS IMPLÍCITOS}

Como se examinó en los apartados anteriores del presente artículo, el acto judicial generador de derechos implícitos representa una instancia de creación judicial, no de interpretación. Sin embargo, dicha actuación debe reconocer límites, cuestión que es demandada por la noción de Estado de Derecho reconocida por la propia CIADH y la doctrina.

\footnotetext{
89 DiCEY (1897) p. 185.

90 Besson (2010) p. 173.

91 Véase: JUAN GELMAN CON URUGUAY (2011).
} 
Para satisfacer esta exigencia se propondrán algunos criterios que buscan establecer ciertas restricciones u orientaciones a la discrecionalidad de la Corte.

\subsection{La naturaleza del Derecho InTERnacional y EL PRINCIPIO DE SUbSidiariedAD}

Tal como se mencionaba en el apartado anterior, uno de los factores que limita el ejercicio de la función jurisdiccional por parte del adjudicador es la naturaleza del Derecho aplicable. Tratándose de las normas del Derecho Internacional, este aún es, en su mayor parte, un Derecho fundado en el acuerdo, expreso o tácito, de los Estados que conforman la comunidad internacional ${ }^{92}$. Por tanto, las organizaciones internacionales, como la CIADH, solo están autorizadas para ejercer las atribuciones expresa y específicamente otorgadas por los mismos Estados y de la forma manifestada por aquellos.

En efecto, cuando los Estados generan una convención de derechos humanos, ellos se obligan a aquello expresamente señalado en el texto del tratado y bajo los términos que ellos entendieron al momento de celebrarlo. La razón es simple: los Estados, al tiempo de ratificar un tratado, deben conocer cuáles son las obligaciones que adquieren para poder ejecutarlas en el futuro. Esto es, como se vio anteriormente, una demanda mínima del Estado de Derecho ${ }^{93}$.

Por tanto, cuando las cortes internacionales, y en especial las de derechos humanos, analizan casos cuyo objeto es decidir si alguno de los Estados cumplió sus obligaciones, dichas cortes deben considerar cuál fue el alcance que los Estados quisieron dar a la obligación en cuestión o bien el sentido que los mismos estados le asignaron con posterioridad a través de la práctica generalizada. De lo contrario, los jueces les estarían imponiendo obligaciones no consentidas. Es por ello que cuando las cortes internacionales analizan este tipo de casos, deben aplicar criterios interpretativos de tipo restrictivo, evitando generar nuevas obligaciones para los Estados o ampliar las ya ratificadas por los mismos. Ello a menos que la práctica generalizada de los mismos Estados muestre que ha surgido una nueva interpretación acerca de esas obligaciones. Por lo demás, así lo reconoció, por ejemplo, la Corte Permanente de Justicia Internacional, predecesora de la actual Corte Internacional de Justicia ${ }^{94}$.

El sistema del Derecho Internacional no representa un caso focal de sistema jurídico, en la medida que no existen dentro de este órganos con poder suficiente para ejercer funciones ejecutivas, legislativas y judiciales y así coordinar eficaz y adecuadamente a todos los actores del sistema ${ }^{95}$. Aún más; dichos órganos a su vez sufren, muchas veces, de un déficit de autoridad frente a los Estados que impide que estos puedan transferir en plenitud más

\footnotetext{
2 CASSESe (2005) p. 4.

93 Golder CON REINO UNIDO (1975) Voto disidente Juez Sir Gerald Fitzmaurice, párrafos 29-30.

94 S.S. Wimbledon (1923) párrafo 25.

95 Hart (1994) p. 214. Seguimos acá la distinción desarrollada por Finnis entre caso "focal” o "central” y caso "periférico". El caso "central" representa la instancia paradigmática de un concepto, mientras que el caso "periférico" representa una instancia del mismo que, si bien comparte elementos comunes con el caso central, carece de otros. Así, se dice que el sistema jurídico internacional no representa un caso focal de sistema jurídico en la medida que, dado su estadio de desarrollo y pese a su creciente complejidad, carece de los elementos suficientes para coordinar a los actores del mismo. Por tanto, representa un caso periférico de sistema jurídico en relación al caso central que estaría representado por los sistemas jurídicos domésticos. Para profundizar en torno a la distinción, véase: FinNis (2011a) pp. 9-11.
} 
atribuciones a los mismos. Ello en la medida que los mismos Estados no están completamente ciertos de la imparcialidad y justicia con la que los organismos internacionales actúan ${ }^{96}$. En ese sentido, VERDUgo y GarCía han criticado la excesiva politización de los actores del sistema interamericano, factor que -a juicio de dichos autores- incidiría en la legitimidad de las decisiones adoptadas por los órganos del mismo sistema ${ }^{97}$. En ese contexto, parecería entonces razonable que - para evitar esa crítica de legitimidad- la CIADH actuase con sentido de prudencia y disciplina institucional.

Otro factor que restringe la discrecionalidad del juez internacional es el principio de subsidiariedad. Los sistemas regionales de derechos humanos tienen naturaleza subsidiaria; esto es, ellos existen para prevenir y reparar violaciones a los derechos humanos cuando los Estados no sean capaces por sí mismos de hacerlo ${ }^{98}$. Ello trae aparejado como consecuencia que los Estados son los primariamente llamados a especificar los derechos contenidos en las convenciones internacionales. Fundamentalmente, esto permite afirmar que la legislación nacional (en sentido amplio) representa el caso central o focal de especificación de convenciones internacionales de derechos humanos. En consecuencia, las decisiones legislativas de la CIADH representarán casos periféricos de dicha especificación.

Continuando con lo anterior, es posible señalar que, en la práctica, los primeros llamados a implementar y dotar de precisión normativa a los preceptos de textura abierta de la Convención son los propios Estados. En ese sentido, la misma CIADH ha manifestado que: "El Estado es el principal garante de los derechos humanos de la personas, de manera que, si se produce un acto violatorio de dichos derechos, es el propio Estado quien tiene el deber de resolver el asunto a nivel interno y reparar antes de tener que responder ante instancias internacionales como el sistema interamericano de protección de los derechos humanos, lo cual deriva del carácter subsidiario que reviste el proceso internacional frente a los sistemas nacionales de garantías de los derechos humanos. Los tribunales internos y órganos estatales tienen el deber de asegurar la implementación de la Convención Americana a nivel nacional"99.

El carácter subsidiario del sistema permite que sean los estados los primeros llamados a especificar las normas de la Convención. En ese sentido, "la supervisión internacional siempre es tardía y generalmente ex post facto» ${ }^{100}$. Por tanto, "cuando una cuestión ha sido resuelta definitivamente en el orden interno según (...) la Convención, no es necesario traerla [a la Corte] para su aprobación o confirmación» ${ }^{101}$.

En efecto, son los Estados quienes tienen la responsabilidad primaria de compatibilizar el ejercicio de los distintos derechos señalados en la Convención mediante la dictación de normas legales que permitan orientar de forma suficiente el actuar de los ciudadanos. Dichas normas, en términos generales, buscarán acomodar el ejercicio de los distintos derechos

\footnotetext{
96 FinNis (2011b) p. 148.

97 Verdugo y García (2012) pp. 190-194.

98 Carozza (2003) p. 59-63.

99 AceVedo Jaramillo y otros con Perú (2006) párrafo 66.

100 Medina y Nash (2011) p. 8.

101 Las Palmeras con Colombia (2001) párrafo 33.
} 
fundamentales a "las justas exigencias del bien común", tal como lo indica el propio artículo 32.2 de la Convención Americana. Dicho acomodo legislativo incluirá determinar «los sujetos de derechos, los obligados por el derecho, el contenido y la extensión tanto del derecho como de la obligación (incluidas las circunstancias y condiciones bajo las cuales el derecho se adquiere), las circunstancias y condiciones bajo las cuales el sujeto de derecho pierde o puede renunciar a su derecho, las consecuencias que surgen de la imposibilidad de la ejecución de la obligación tanto para el sujeto del derecho como para el obligado, etc.» ${ }^{102}$.

\subsection{El EFECTO RELATIVO DE LAS SENTENCIAS DE la CIADH}

Un segundo elemento que restringe el proceso creativo de la CIADH es el efecto inter partes de sus sentencias. En efecto, el artículo 68 de la Convención Americana prescribe que «los Estados partes en la Convención se comprometen a cumplir la decisión de la Corte en todo caso en que sean partes». En ese sentido, las decisiones de la Corte tienen efectos relativos y no erga omnes.

El alcance relativo de sus sentencias debe mover a los jueces interamericanos a ejercer ciertas dosis de self-restraint o autocontrol en sus procesos creativos. Este factor limitante ha sido relativizado por la CIADH a través del recientemente creado control de convencionalidad, el que obliga a los Estados y a sus autoridades a aceptar como definitiva toda interpretación y especificación de derechos efectuada por la Corte, independientemente si los Estados fueron o no parte del caso concreto resuelto por ella ${ }^{103}$. A este respecto, la extensión de potestades por medio de la vía judicial no parece ser plenamente compatible con las exigencias impuestas por el estado de Derecho ${ }^{104}$. Ello en la medida que se crea una obligación respecto de la cual los Estados no consintieron con claridad al momento de ratificar la Convención Americana.

\subsection{Los MeCANismos de REFORMA establecidos en la CONVENCión}

En tercer lugar, la propia Convención establece mecanismos formales para su reforma. En efecto, el artículo 31 del tratado, bajo el epígrafe "reconocimiento de otros derechos", afirma que existe la posibilidad de que otros derechos y libertades sean incluidos en el "régimen de protección de esta Convención". Sin embargo, esa incorporación debe ser efectuada "de acuerdo a los procedimientos establecidos en los artículos 76 y 77 " de la misma Convención Americana.

En ese sentido, el artículo 76.1 del tratado establece que "cualquier Estado parte directamente y la Comisión o la Corte por conducto del Secretario General, pueden someter a la Asamblea General [de la Organización de Estados Americanos], para lo que estime conveniente, una propuesta de enmienda a esta Convención». Por tanto, el órgano llamado a introducir enmiendas al texto de la Convención no es la CIADH, sino los propios Estados a través de la Asamblea General de la Organización de Estados Americanos. Asimismo,

\footnotetext{
102 Webber (2011) p. 137.

103 Almonacid ARellano y otros con Chile (2006) párrafo 124.

104 Para una visión crítica de la idea tradicional acá señalada que el Derecho legislado debe sujetar la actuación de los jueces en conformidad a los dictados del Estado de Derecho, véase: Ferrajoli (2004) p. 100.
} 
el artículo 77 de la Convención autoriza a los propios Estados para generar protocolos adicionales que permitan «incluir progresivamente en el régimen de protección de la misma otros derechos y libertades». Estas son las dos modalidades contempladas por la Convención para su reforma. Por tanto, la CIADH no puede, so pretexto de interpretar, derogar o bien adicionar nuevos derechos no contemplados por el tratado. Lo que la CIADH sí puede hacer es, en conformidad al artículo 77, recomendar a la Asamblea General la modificación de la Convención. Este último es, entonces, el camino que la CIADH debe seguir si desea promover una reforma a la Convención.

Por último, cabe hacerse cargo de una problemática adicional: una supuesta contradicción interna entre lo dispuesto en los artículos 29 letra c) y 76 de la Convención. El primero pareciera sugerir que la enumeración de derechos incluida en el tratado no sería cerrada y, por tanto, podrían perfectamente existir otros derechos que no se encuentren considerados en ella, pero que sí gocen de la protección de la Convención. Por otro lado, el segundo establece que es en la Asamblea General de la Organización de Estados Americanos (OEA) donde debe discutirse cualquier reforma a la Convención que, por ejemplo, busque incorporar el reconocimiento de otros derechos. Pareciera que estas dos disposiciones estuviesen en conflicto. En este contexto, es necesario buscar una interpretación de ambas disposiciones que permita armonizarlas y preservar la coherencia interna del sistema interamericano de derechos humanos ${ }^{105}$.

Gros plantea que ambas normas no son incompatibles: la sola referencia efectuada por el artículo 76 «no excluye la también aceptación de la existencia de otros derechos, que asimismo gozarán del régimen convencional de protección, siempre que ellos fueran ‘inherentes al ser humano' o que se 'deriven' de la 'forma democrática representativa de gobierno'» ${ }^{106}$. Por último, agrega Gros, tanto la Comisión Interamericana de Derechos Humanos como la CIADH serían los órganos llamados a identificar y custodiar dichos derechos no enumerados en la medida que satisfagan el estándar establecido en el artículo 29 letra c) ${ }^{107}$.

Sin embargo, la posición de Gros es problemática. En efecto, el artículo 29 letra c) de la Convención no debe ser leído como una habilitación tácita (implied power) en favor de la CIADH para incorporar todo tipo de derechos en la Convención. Dicha interpretación sería imposible a la luz de lo prescrito por los artículos 76 y 77 . En efecto, estas normas gozarían de preferencia en su aplicabilidad debido a su especialidad. Así, mientras el artículo 29 letra c) busca dar orientaciones al juez respecto a la interpretación de la Convención, el artículo 76 tiene por objeto definir ciertas reglas relativas a la incorporación de derechos al texto de la Convención. Pretender que el artículo 29 letra c) permite al juez Interamericano incorporar derechos no enumerados al texto de la Convención sería incompatible incluso con lo señalado en el propio artículo $1^{\circ}$ del tratado, el que indica que, mediante su ratificación, los Estados «se comprometen a respetar los derechos y libertades reconocidos en [la Convención]» $\mathrm{y}$, por tanto, no aquellos que la CIADH estime necesario incluir.

\footnotetext{
105 Gros (2000) p. 171.

106 Gros (2000) p. 171.

107 Gros (2000) p. 171.
} 
Asimismo, la interpretación propuesta por Gros ampliaría radicalmente el campo de la jurisdicción ratione materiae de la $\mathrm{CIADH}$, cuyos límites, si es que los existiesen en este contexto, serían extremadamente difusos. Si aceptáramos la posibilidad de que la CIADH puede incluir todo tipo de derechos en la Convención sin una reforma formal previa del tratado, se crearía un espacio de discrecionalidad difícilmente aceptable desde la perspectiva del estado de Derecho. Esto porque se reconocería al órgano judicial del sistema una potestad reformadora que no le está reconocida en el texto de la Convención. De hecho, una interpretación de esa naturaleza «aumenta el campo para la arbitrariedad, disminuye la posibilidad de que los jueces sean sujetos a control por otros órganos (...) y disminuye las posibilidades de que los jueces traten casos similares de forma parecida ${ }^{108}$. Es por ello que, cualquiera sea la extensión de la jurisdicción asignada a una corte internacional de derechos humanos, siempre deben fijarse límites a aquella ${ }^{109}$. Por tanto, la mencionada interpretación del artículo 29 letra c) de la Convención debe ser desechada.

De hecho, la necesidad de establecer límites a la discrecionalidad de la Corte fue reconocida por la propia CIADH en sus primeros años. Efectivamente, en el asunto Viviana Gallardo, la Corte manifestó que si bien el objeto principal del sistema interamericano era proteger los derechos esenciales de la persona humana, los mecanismos para lograrlo eran aquellos que los mismos Estados habían consentido ${ }^{110}$. En ese contexto, la tarea de la CIADH era "garantizar la protección internacional que establece la Convención [respecto de los derechos] dentro de la integridad del sistema pactado por los Estados» ${ }^{11}$. Por tanto, la interpretación del articulado de la Convención debía favorecer y potenciar los derechos humanos «siempre que ello no impli[cara] una alteración del sistema» ${ }^{112}$. En ese sentido, los órganos del sistema interamericano tienen una doble función: por un lado, deben propender a generar interpretaciones de las normas de derechos fundamentales contenidas en la Convención que potencien la protección de las garantías reconocidas en la misma y, por otro, deben preservar la articulación del sistema de protección respecto del cual los Estados consintieron al momento de ratificar la Convención y otorgar jurisdicción a la CIADH.

Fundado en lo anterior, se propondrá, entonces, una interpretación alternativa a aquella planteada por Gros. Ella, custodiando la orgánica interna del tratado, no restringe el reconocimiento de derechos no enumerados en la Convención. De acuerdo a esta interpretación, el artículo 29 letra c) de la Convención buscaría permitir a los Estados, tanto dentro de su legislación doméstica como en otros tratados celebrados por aquellos, reconocer otros derechos que no se encuentren contenidos en la Convención y darles protección tanto a nivel nacional como internacional. Esto por cuanto los derechos establecidos en la Convención representan un mínimo a respetar por parte de los Estados. Sin embargo, ello no es óbice para que dicho piso de protección pueda ser ampliado por los Estados a través de su propia legislación o bien mediante tratados celebrados entre ellos. Este es el real al-

\footnotetext{
108 Heydon (2011) p. 28.

109 Burgorgue-Larsen \& Úbeda de Torres (2011) p. 67.

110 AsUnto ViVIANA GALLARDo (1981) párrafo 16.

111 AsUNTO VIVIANA GALLARDO (1981) párrafo 16.

112 Asunto ViVIana GaLlardo (1981) párrafo 16.
} 
cance del artículo 29 letra c): evitar que los Estados entiendan que no pueden ir más allá de lo establecido en la Convención en relación a los derechos y libertades allí reconocidas. En ese sentido, el artículo 29 letra c) es expresivo de la idea de que "los tratados no conceden derechos humanos sino que solo los reconocen y que pueden existir derechos humanos que no han sido formalmente reconocidos en un cuerpo jurídico" ${ }^{113}$.

La interpretación propuesta permite cumplir con dos objetivos: (a) primero, respetar la distribución de competencias establecida en forma de regla en el artículo 76 de la Convención, con lo que se asegura la corrección funcional del sistema; y (b) segundo, permitir nuevos desarrollos de derechos humanos dentro de la esfera legislativa doméstica e, incluso, internacional. En ese sentido, los mismos Estados han ampliado o incluso especificado la esfera de protección de la Convención mediante la suscripción y ratificación de protocolos adicionales celebrados en conformidad al artículo 77 de la Convención Americana ${ }^{114}$. Por tanto, no se puede afirmar que las reglas previstas en los artículos 76 y 77 del tratado hubiesen impedido la ampliación del catálogo de derechos protegidos por el sistema interamericano. De hecho, el propio Gros termina concluyendo que la utilización de los mecanismos señalados en los artículos 76 y 77 tienen la ventaja de permitir la inclusión de nuevos derechos al sistema de protección interamericano de forma "expresa, indiscutible, precisa y clara" 115 , lo que va, precisamente, en la dirección de las demandas planteadas por el estado de Derecho.

\subsection{El teXto de la propia Convención}

Un cuarto elemento a tener en cuenta por la CIADH es la serie de derechos expresamente consagrados en la Convención Americana. Ellos operan como un límite al juez interamericano en la medida que sería altamente complejo para el sistema que los jueces encontrasen en el texto de la Convención derechos implícitos que fueren incompatibles con el texto expreso de otras normas de derechos fundamentales. Esto queda en evidencia al analizar el tenor del artículo $1^{\circ}$ de la propia Convención, que señala que "los Estados partes en esta Convención se comprometen a respetar los derechos y libertades reconocidas en ella”.

Uno de esos límites son las denominadas prohibiciones absolutas contenidas por la Convención. En ese sentido, los tratados internacionales de derechos humanos, como la Convención Americana o el Convenio Europeo de Derechos Humanos, contienen catálogos de derechos que carecen, por regla general, de suficiente especificidad. La gran excepción a aquello corresponde a los derechos humanos absolutos, los que aparecen en ambas convenciones regionales explicitados no en términos de derechos, sino de prohibiciones absolutas ${ }^{116}$. Ellas sí tienen suficiente densidad normativa para generar una obligación directa para el Estado ${ }^{117}$. Dichas prohibiciones absolutas reconocidas por la Convención represen-

\footnotetext{
113 Medina (2003) p. 6.

114 Consideremos, para estos efectos, el protocolo adicional sobre derechos económico-sociales (1988) y el protocolo adicional relativo a la prohibición de la pena de muerte (1990).

115 Gros (2000) p. 171.

116 FinNis (2011a) p. 211.

117 Filartiga v. Peña-IRala (1980) p. 882.
} 
tan un límite absoluto a la creatividad judicial. En ese sentido, los jueces interamericanos no podrían crear derechos implícitos que fuesen contrarias a esas prohibiciones.

Esta tensión entre prohibiciones absolutas y derechos implícitos aparece, por ejemplo, a propósito de la inclusión de los derechos reproductivos y el acceso a tecnologías médicas en la Convención. En Artavia Murillo, la CIADH crea un tipo de derecho de acceso a tecnologías que faciliten los procesos de fertilización asistida ${ }^{118}$. Sin embargo, en la práctica, dichos procesos efectivamente pueden infringir la prohibición del artículo 4.1 que señala que "nadie puede ser privado de su vida arbitrariamente". Dicha prohibición, de acuerdo a la misma disposición, es impuesta a los Estados "en general, a partir del momento de la concepción”. En efecto, ciertos procesos de fertilización asistida atentan directamente contra la vida del embrión o bien pueden crear para su vida un riesgo absolutamente desproporcionado. En ese sentido, el derecho implícito injertado en la Convención por la CIADH en Artavia Murillo aparece en contradicción con la prohibición absoluta del artículo 4.1.

El resto de los derechos contenidos en la Convención Americana -aun en su indeterminación semántica- también representan un tipo de límite a la discrecionalidad de la CIADH para formular derechos implícitos. Ello porque la Corte debe ser cuidadosa de no generar derechos cuyo contenido aparezca en franca oposición a alguna de aquellas garantías establecidas en la propia Convención.

Así, tratándose de la problemática asociada al derecho a la verdad y al castigo penal efectivo, esa tensión entre derechos implícitos y explícitos ha quedado en evidencia en la sentencia de la Corte Suprema uruguaya que declaró la inconstitucionalidad de ciertas disposiciones de la Ley No 18.831, dictada por el Congreso Nacional de aquel país para ejecutar la sentencia Gelman con Uruguay. En este caso, la CIADH declaró que la Ley No 15.848 de Caducidad de la Pretensión Punitiva del Estado -votada favorablemente por un Congreso democráticamente y ratificada en dos ocasiones mediante referéndum popularera incompatible en abstracto con la Convención Americana. La ley en cuestión declaraba la caducidad del ejercicio de la pretensión punitiva del Estado "respecto de los delitos cometidos hasta el $1^{\circ}$ de marzo de 1985 por funcionarios militares y policiales, equiparados y asimilados por móviles políticos o en ocasión del cumplimiento de sus funciones y en ocasión de acciones ordenadas por los mandos que actuaron durante el período de facto".

En la medida que la ley impedía la persecución penal en dichos casos, la CIADH declaró que el precepto legal infringía el derecho a la verdad y al castigo penal efectivo, ambos derechos implícitos en la Convención ${ }^{119}$. Después de Gelman, el estado de Uruguay implementó la sentencia a través de la dictación de la Ley No 18.831 el año 2011. Dicha ley declaró restablecido en su artículo $1^{\circ}$ "el pleno ejercicio de la pretensión punitiva del Estado para los delitos cometidos en aplicación del terrorismo de Estado hasta el $1^{\circ}$ de marzo de 1985”. Para ello declaró, al tenor del artículo $3^{\circ}$ de la ley, como crímenes de lesa humanidad y, por tanto, imprescriptibles, los delitos señalados en el artículo $1^{\circ}$ de la misma ley. Además, el artículo $2^{\circ}$ de la Ley No 18.831 declaró que todos los plazos de caduci-

\footnotetext{
118 ArtaVia Murillo y otros (FECUNDACión IN VITRO) CON Costa Rica (2012) párrafo 150.

119 GELMAN CON URUGUAY (2010) párrafos 243-244.
} 
dad o prescripción que beneficiaran o hubiesen beneficiado a los afectados se entendían no cumplidos para efectos de concretar la persecución penal.

Fue entonces cuando un grupo de afectados decidió solicitar a la Corte Suprema uruguaya la declaración de inconstitucionalidad de ciertas normas de la Ley No 18.831 que permitían la reapertura de la persecución penal en su contra. Esto porque la ley infringía las garantías constitucionales asociadas al debido proceso y a la prohibición de retroactividad de la ley penal. La Corte Suprema, en sentencia de 22 de febrero de 2013, no solo efectuó un control de constitucionalidad respecto de la ley impugnada, sino que también analizó la ley impugnada a la luz de la Convención Americana ${ }^{120}$. En este respecto, la Corte afirmó que el Estado de Uruguay había ratificado dicho tratado y se encontraba sujeto al mismo, por lo que "nunca cabría soslayar principios constitucionales (...) del propio Estado que acepta la jurisdicción de la Corte Interamericana, como tampoco los que imponen los referidos sistemas americano y universal de protección de derechos" ${ }^{121}$. En ese contexto, la Corte Suprema afirmó que "nada puede justificar que el Estado (...) deba o pueda llevar a cabo acciones que sean contrarias a los derechos humanos reconocidos (...) por su legislación interna, tanto como por la normativa [internacional]"122.

Aplicando la referida doctrina, la Corte Suprema uruguaya concluyó que los artículos $2^{\circ}$ y $3^{\circ}$ de la Ley No 18.831 infringían no solo la Constitución del Estado sino también la Convención Americana. Ello en la medida que la ley importaba una infracción de normas de la Convención, tales como la prohibición de la retroactividad en materia penal (artículo $9^{\circ}$ ) y aquella que establece que el inculpado absuelto por sentencia con fuerza de cosa juzgada no puede ser sometido a un nuevo juicio por los mismos hechos (artículo $8.4)^{123}$. Dichos derechos, señaló la Corte Suprema, no eran susceptibles de ser derogados ni siquiera en estados de excepción, tal como lo señalaba el artículo 27 de la propia Convención $^{124}$. En ese contexto, el derecho a la verdad y al castigo penal efectivo implementados por la Ley No 18.831 serían incompatibles con las garantías del debido proceso establecidas en la propia Convención Americana.

Como es posible de apreciar, la creación jurisprudencial de derechos implícitos por parte de la CIADH puede generar serias problemáticas conceptuales dentro del sistema interamericano en la medida que dichos derechos pueden, en abstracto y en concreto, ser contrarios a derechos explícitamente garantizados en la Convención.

120 AA.BB. Denuncia. Excepción de Inconstitucionalidad Artículos $1^{\circ}, 2^{\circ}$ y $3^{\circ}$ de la Ley $N^{o}$ 18.831, IUE 2-109.9717/2011 (2013) pp. 9-11.

121 AA.BB. Denuncia. Excepción de Inconstitucionalidad Artículos $1^{\circ}, 2^{\circ}$ y $3^{\circ}$ de la Ley $N^{o}$ 18.831, IUE 2-109.9717/2011 (2013) pp. 9-10.

122 AA.BB. Denuncia. Excepción de Inconstitucionalidad Artículos $1^{\circ}, 2^{\circ}$ y $3^{\circ}$ de la Ley $N^{o}$ 18.831, IUE 2-109.9717/2011 (2013) p. 10.

${ }_{123}$ AA.BB. Denuncia. Excepción de Inconstitucionalidad Artículos $1^{\circ}, 2^{\circ}$ y $3^{\circ}$ de la Ley $N^{o}$ 18.831, IUE 2-109.9717/2011 (2013) p. 10

124 AA.BB. Denuncia. Excepción de Inconstitucionalidad Artículos $1^{\circ}, 2^{\circ}$ y $3^{\circ}$ de la Ley $N^{o}$ 18.831, IUE 2-109.9717/2011 (2013) p. 10. 


\section{CONCLUSIÓN}

La CIADH, a través de su interpretación de las normas de la Convención Americana, ha reconocido la existencia de derechos implícitos, esto es, derechos no señalados de forma expresa en la misma. Dicha práctica, pese al carácter interpretativo que la propia Corte ha tratado de asignarle, representa instancias de creación judicial que no se condicen con las exigencias del estado de Derecho. Ello por cuanto implica la vulneración de la idea de legalidad, que exige que la Corte actúe en conformidad a las potestades entregadas de forma previa por la Convención. Finalmente, se concluye que la problemática planteada encuentra solución en la propia Convención, la que ofrece factores que buscan, efectivamente, limitar las potestades de la Corte.

\section{BIBLIOGRAFÍA CITADA}

Aldunate, Eduardo (2008): Derechos fundamentales (Santiago de Chile, LegalPublishing). Atria, Fernando (2001): On law and legal reasoning (Portland, Hart Publishing).

Ayala, Carlos (2007): "La ejecución de sentencias de la Corte Interamericana de Derechos Humanos” en Estudios Constitucionales, año 5 No 1: pp. 127-201.

BARNETT, Randy (2004): Restoring the lost constitution: the presumption of liberty (Princeton, Princeton University Press).

BESSON, Samantha: "Theorizing the sources of international law", en Besson, Samantha y Tasioulas, John (edit.): The philosophy of international law (Oxford, Oxford University Press) pp. 163-185.

BuCHANAN, Allen (2010): “The legitimacy of international law", en BESSON, Samantha y Tasioulas, John (edit.): The philosophy of international law (Oxford, Oxford University Press) pp. 79-96.

Burgorgue-Larsen, Laurence \& Úbeda de Torres, Amaya (2011): The Inter-American court of human rights. Case law and commentary (Oxford, Oxford University Press).

Burgorgue-Larsen, Laurence (2014): "El contexto, las técnicas y las consecuencias de la interpretación de la Convención Americana de Derechos Humanos", Estudios Constitucionales, año 12 No 1: pp. 105-106.

Candia, Gonzalo (2014): "Analizando la tesis de los derechos implícitos: comentario a la sentencia del Tribunal Constitucional recaída sobre el requerimiento de inaplicabilidad Rol No 2.408-2013 de 6 de marzo de 2014”, Revista de Derecho de la Universidad Católica del Norte, vol. 21 No 1: pp. 497-521.

Carrió, Genaro (1989): "Sobre la creación judicial del derecho", Cuadernos de Análisis Jurídico, No 8, pp. 35-49.

CARrIó, Genaro (1994): Notas sobre derecho y lenguaje (Buenos Aires, Abeledo-Perrot) 416 pp.

Contreras, Pablo (2011): “¿Derechos implícitos? Notas sobre la identificación de normas de derecho fundamental”, en NúNEz, José Ignacio (edit.): Nuevas perspectivas en derecho público (Santiago de Chile, Librotecnia) pp. 149-185.

DiCEY, Albert V. (1897): Introduction to the study of the law of the constitution (Londres, MacMillan, 5a ed.) 
FARER, Tom (2004): "The rise of the Inter-American human rights regime: no longer a unicorn, not yet an ox", en Harris, David \& Livingstone, Stephen (edit.), The InterAmerican system of human rights (Oxford, Oxford University Press) pp. 31-64.

FERRAJOlI, Luigi (2004): Las razones jurídicas del pacifismo (Madrid, Trotta).

FINNIS, John (2011a): Natural law and natural rights (Oxford, Oxford University Press, 2a ed.)

FinNis, John (2011b): "A grand tour of legal theory", en Finnis, John, Philosophy of law: Collected essays. Vol. IV (Oxford, Oxford University Press) pp. 91-155.

Fuller, Lon L. (1969): The morality of law (New Haven, Yale University Press, 2a ed.).

Fuller, Lon L. (1978): “The form and limits of adjudication”, Harvard Law Review, vol. 92: pp. 353-409.

García, Sergio y Morales, Julieta (2011): “Consideraciones sobre el principio de legalidad penal en la jurisprudencia de la Corte Interamericana de Derechos Humanos", Revista Mexicana de Derecho Constitucional, No 24: pp. 195-246.

Goldsworthy, Jeffrey (2011): “The case for originalism”, en Huscroft, Grant \& Miller, Bradley W. (edit.), The challenge of originalism. Theories of constitutional interpretation (Cambridge: Cambridge University Press) pp. 42-69.

Carozza, Paolo (2003): "Subsidiarity as a structural principle of international human rights law”, American Journal of International Law, vol. 97: pp. 59-63.

Cassesse, Antonio (2005): International law (Oxford, Oxford University Press, segunda edición).

Fix-Zamudio, Héctor (2011): "Prólogo" en Ventura, Manuel, Estudios sobre el Sistema interamericano de protección de derechos humanos, tomo II (San José de Costa Rica, Instituto Interamericano de Derechos Humanos) pp. XXXIX-L.

Gros Espiell, Héctor (2000), "Los derechos humanos no enunciados o no enumerados en el constitucionalismo americano y en el artículo 29. c) de la Convención Americana sobre Derechos Humanos", Anuario Iberoamericano de Justicia Constitucional, No 4: pp. $145-173$.

HARrIS, David (2004): "Regional protection of human rights: the Inter-American achievement", en Harris, David \& Livingstone, Stephen (edit.), The Inter-American system of human rights (Oxford, Oxford University Press) pp. 1-30.

Hart, Herbert (1958): "Positivism and the separation of law and morals", Harvard Law Review, vol. 71 No4: pp. 593-629.

HarT, Herbert (1994): The concept of law (Oxford, Oxford University Press, segunda edición) $315 \mathrm{pp}$.

HeYdon, Dylon (2011): "What do we mean by the Rule of Law?" en EkIns, Richard (edit.), Modern challenges to the rule of law (Wellington, LexisNexis NZ Limited) pp. 15-45.

LEÓN, Carolina (2010): La interpretación de los derechos fundamentales según los tratados internacionales sobre derechos humanos (Madrid, editorial Reus) 328 pp.

Malarino, Ezequiel (2010): "Activismo judicial, punitivización y nacionalización. Tendencias antidemocráticas y antiliberales de la corte interamericana de derechos humanos", en Grupo Latinoamericano de Estudios sobre Derecho Penal Internacional (edit.), Sistema interamericano de protección de los derechos humanos y derecho penal internacional (Montevideo, Fundación Konrad Adenauer) pp. 25-61. 
Medina, Cecilia (2003): La convención Americana: teoría y jurisprudencia (Santiago de Chile, Centro de Derechos Humanos de la Universidad de Chile).

Medina, Cecilia \& Nash, Claudio (2011): Sistema interamericano de derechos humanos: introducción a sus mecanismos de protección (Santiago de Chile, Centro de Derechos Humanos de la Universidad de Chile, segunda edición).

Medina, Cecilia (2013): "The role of international tribunals: law-making or creative interpretation", en SHELTON, Dinah (ed.), The Oxford Handbook of International Human Rights Law (Oxford University Press, Oxford) pp. 649-669.

Nino, Carlos (2000): Fundamentos de derecho constitucional (Buenos Aires, editorial Astrea, segunda edición).

Nogueira, Humberto (2007): "Los derechos humanos contenidos en tratados de derechos humanos como parte del parámetro de control de constitucionalidad: la sentencia rol No 786-2007 del tribunal constitucional", Estudios Constitucionales, Año 5 No 2: pp. 457-466.

Organización de Estados Americanos (1969), Conferencia Especializada Interamericana sobre Derechos Humanos. Actas y Documentos (OEA/Ser.K/XVI/1.2).

PASQualucci, Jo M. (2012): The practice and procedure of the Inter-American Court of Human Rights (New York, Cambridge University Press, segunda edición).

Pérez, Antonio (1991): La seguridad jurídica (Barcelona, Ariel).

RAZ, Joseph (2002): "El estado de derecho y su virtud" (Rolando Tamayo, traductor) en Carbonell, Miguel et al. (ed.): Estado de derecho. Concepto, fundamentos y democratización en América Latina (México D.F., Siglo XXI) pp. 15-36.

Sollum, Lawrence (2006): “The Supreme Court in bondage: constitutional stare decisis, legal formalism, and the future of unenumerated rights", University of Pennsylvania Journal of Constitutional Law, vol. 9: pp. 155-208.

Sollum, Lawrence (2010): “The interpretation-construction distinction", Constitutional Commentary, vol. 27 No1: pp. 95-118.

Summers, Robert (2002): "Los principios del estado de derecho" (Pablo Larrañaga, trad.) en Carbonell, Miguel et al. (ed.): Estado de derecho. Concepto, fundamentos y democratización en América Latina (México D.F., Siglo XXI) pp. 37-60.

Verdugo, Sergio \& García, José Francisco (2012): "Radiografía al sistema interamericano de derechos humanos”, Actualidad Jurídica, No 25, 2012: pp. 175-216.

WALDRON, Jeremy (2006): “The rule of international law”, Harvard Journal of Law \& Public Policy, vol. 30 No 1: pp. 15-30.

WeBber, Gregoire (2011): The negotiable constitution. On the limitation of rights (Cambridge: Cambridge University Press).

Whittington, Keith (1999): Constitutional interpretation. Textual meaning, original intent, and judicial review (Lawrence, Kansas University Press).

Yowell, Paul (2012): "Legislación, common law y la virtud de la claridad" (Gonzalo Candia, trad.), Revista Chilena de Derecho, vol. 39 No 2: pp. 481-512.

ZaGrebelsky, Gustavo (2008): "Realismo y concreción del control de constitucionalidad de las leyes en Italia”, Estudios Constitucionales, Año 6, No 1, 2008: pp. 325-335. 


\section{NORMAS CITADAS}

Convención de Viena sobre Derecho de los tratados, Organización de Naciones Unidas, suscrita el 23 de mayo de 1969.

Convención sobre la eliminación de todas las formas de discriminación contra la mujer, Organización de Naciones Unidas, suscrita el 18 de diciembre de 1979.

Convención Americana sobre derechos humanos suscrita en la conferencia especializada Interamericana sobre derechos humanos, 7-22 de noviembre de 1969, Pacto de San José de Costa Rica.

Protocolo Adicional a la Convención Americana sobre Derechos Humanos en Materia de Derechos Económicos, Sociales y Culturales "Protocolo de San Salvador". 17 de noviembre de 1988.

Protocolo a la Convención Americana sobre Derechos Humanos Relativo a la Abolición de la Pena de Muerte. 8 de junio de 1990.

Estatuto de la Corte Interamericana de Derechos Humanos. Aprobado mediante Resolución No 448 adoptada por la Asamblea General de la Organización de Estados Americanos en su noveno período de sesiones, celebrado en La Paz, Bolivia. Octubre de 1979.

Uruguay: Ley No 15.848. Funcionarios Policiales y Militares. Se Reconoce que Ha Caducado el Ejercicio de la Pretensión Punitiva del Estado Respecto de los Delitos Cometidos hasta el $1^{\circ}$ de marzo de 1985. Publicada en el Diario Oficial el 28 de diciembre de 1986.

Uruguay: Ley No 18.831. Pretensión Punitiva del Estado. Restablecimiento para los Delitos Cometidos en Aplicación del Terrorismo de Estado hasta el 1 de marzo de 1985. Publicada en el Diario Oficial el 1 de noviembre de 2011.

\section{JURISPRUDENCIA CITADA}

Sentencias de la Corte Permanente de Justicia Internacional

S.S. Wimbledon, 1923 (Serie A) No 1.

Sentencias del Tribunal Europeo de Derechos Humanos

Golder con Reino Unido. Fondo. Sentencia de 21 de febrero de 1975. Aplicación No $4.451 / 70$.

\section{Sentencias de la Corte Interamericana de Derechos Humanos}

ACEVED Jaramillo Y OtROS CON PERÚ. Interpretación de la sentencia de excepciones preliminares, fondo, reparaciones y costas. Sentencia de 24 de noviembre de 2006. Serie C No 157.

Almonacid ARelano y otros con Chile. Excepciones preliminares, fondo, reparaciones y costas. Sentencia de 26 de septiembre de 2006. Serie C No 154.

Asunto ViVIana GaLLARDo. Resolución de 13 de noviembre de 1981. Serie 101.

ARtaVia Murillo y otros (FECUNDACIÓN IN VITRO) CON COSTA Rica. Excepciones preliminares, fondo, reparaciones y costas. Sentencia de 28 de noviembre de 2012. Serie C No 257. 
BENJAMIN Y OtROS CON TRINIDAD Y TOBAGO. Excepciones preliminares. Sentencia de 1 de septiembre de 2001. Serie C No 81.

Blake con Guatemala. Fondo. Sentencia de 24 de enero de 1998. Serie C No 36.

Caso las palmeras con Colombia. Fondo. Sentencia de 2 de diciembre de 2001. Serie C No 90.

Comunidad Indígena YAKYE AXA CON PARAGUAY. Fondo, repararaciones y costas. Sentencia de 17 de junio de 2005. Serie C No 125.

Comunidad Mayagna (Sumo) Awar Tingni con NiCARagua. Fondo, reparaciones y costas. Sentencia de 31 de agosto de 2001. Serie C No 79.

FURLAN Y FAMILIARES CON ARGENTINA. Excepciones preliminares, fondo, reparaciones y costas. Sentencia de 31 de agosto de 2012. Serie C No 246.

GONZÁLEZ Y OTRAS (CAMPO ALGODONERO) CON MÉXICO. Excepción preliminar, fondo, reparaciones y costas. Sentencia de 16 de noviembre de 2009. Serie C No 205.

JUAN GELMAN CON URUGUAY. Fondo y reparaciones. Sentencia de 24 de febrero de 2011. Serie $\mathrm{C} \mathrm{No} 221$.

Niños de la Calle con Guatemala. Fondo. Sentencia de 19 de noviembre de 1999. Serie C No 63.

VARgas AReco con Paraguay. Fondo. Sentencia de 26 de septiembre de 2006. Serie C No 155.

Opiniones Consultivas de la Corte Interamericana de Derechos Humanos

La Expresión "Leyes" en el Artículo 30 de la Convención Americana Sobre Derechos Humanos, OC-6/86, 9 de mayo 1986 (Ser. A) No 6 (1986).

El Habeas Corpus Bajo Suspensión de Garantías (Arts. 27.2, 25.1 y 7.6 Convención Americana Sobre Derechos Humanos), OC-8/87, 30 de enero 1987 (Ser. A) No 8 (1987).

Sentencias de la Corte Suprema de Uruguay

AA.BB. Denuncia. Excepción de Inconstitucionalidad Artículos $1^{\circ}, 2^{\circ}$ y $3^{\circ}$ de la Ley $N^{o}$ 18.831, IUE 2-109.9717/2011 (2013).

Sentencias de Cortes de Estados Unidos

Filartiga V. Peña-IRala, 630 F.2d 876 (2nd Cir. 1980). 